Article

\title{
Analysis of Sustainability Decision Trees Generated by Qualitative Models Based on Equationless Heuristics
}

\author{
Karel Doubravský ${ }^{1, *}$, Alena Kocmanová ${ }^{2}$ and Mirko Dohnal ${ }^{2}$ \\ 1 Department of Informatics, Faculty of Business and Management, Brno University of Technology, Kolejní 4, \\ 61200 Brno, Czech Republic \\ 2 Department of Economics, Faculty of Business and Management, Brno University of Technology, Kolejní 4, \\ 61200 Brno, Czech Republic; kocmanova@fbm.vutbr.cz (A.K.); dohnal@fbm.vutbr.cz (M.D.) \\ * Correspondence: doubravsky@fbm.vutbr.cz; Tel.: +420-54114-3723
}

Received: 30 May 2018; Accepted: 13 July 2018; Published: 18 July 2018

check for updates

\begin{abstract}
Sustainability processes are complex and therefore ill-known, inconsistent, and subjective, and must be studied despite a shortage of information. It is prohibitively difficult to study them on quantitative levels using quantitative methods. The presented qualitative approach enables us to solve these issues. There are just three values used to describe the qualitative variables and their derivatives, plus/increasing, zero/constant, and negative/decreasing. An n-dimensional equation-less qualitative model is a set of pairwise relations. Such relations represent a shallow knowledge of the sustainability systems being studied. The solution of the qualitative model is a set of scenarios. The behaviour of this model is described by all of the possible transitions among these scenarios. A decision maker can easily compile a decision tree if he/she knows all of the possible transitions. The generated tree can be evaluated using traditional methods if all of the relevant probabilities are known. Otherwise, some heuristics are used to evaluate the best decision.
\end{abstract}

Keywords: sustainability; equation-less qualitative model; decision tree; information shortage; heuristics

\section{Introduction}

Sustainability studies represent a broad spectrum of different tasks, for example, environmental analysis, economics, natural resources, and sociology. The majority of these tasks are complex and difficult to measure/observe problems. This requires different methods to satisfy the different aspects of the different sustainability tasks (see, e.g., [1,2]).

Different planning/optimisation algorithms can be used, such as, heuristic, expert systems, and purely statistically based algorithms [2,3]. The majority of the mentioned knowledge items are vague and based on heuristics. For example, "a dominant manufacturer always benefits from its power" (see [4]).

The decision making within sustainability studies and related disciplines is often based on models of unique systems (see, e.g., [5,6]). Conventional statistical methods that are directly or indirectly related to the basic law of large numbers are difficult or impossible to apply (see, e.g., [7,8]). Severe knowledge shortages put pressure on the integration of any available information item. It means that knowledge items of different levels of subjectivity and nature must be taken into consideration in order to develop the best possible model of a unique task under study [9]. However, any efficient integration of such knowledge items of different origins requires common sense reasoning (see, e.g., [10-17]).

Applied artificial intelligence has generated several algorithms that study vagueness without the traditional probabilistic approach. Fuzzy reasoning is one of them (see, e.g., [18]); genetic algorithms are another example $[19,20]$. 
Human brains solve the tasks that are out of reach of any algorithm that can be made computer available. Common sense formalisation has attracted attention a long time ago (see, e.g., ideas related to naïve physics) $[12,21]$. Some examples of human-like reasoning include commonly understood, intuitive, or everyday-observed rules of nature, for example (see, e.g., [22]):

- A dropped object falls straight down.

- A solid object cannot pass through another solid object.

- A vacuum sucks things towards it.

Sustainability problems related to environmental economics and management often suffer from a different shortage of information and/or knowledge items [23-25]. The available network of knowledge items is usually very sparse. This is particularly important in relation to a broad spectrum of sustainability tasks, because of their interdisciplinary nature [26-28]. Moreover, new algorithms will be accepted and used if they do not require an extensive study of complex theories, and the results can be easily rechecked using just common sense. These are the main reasons a qualitative reasoning method has been used in this paper (see, e.g., [29,30]).

Many knowledge items are only available as verbal descriptions based on trends, for example, decreasing, constant, and increasing. For example,

"if the ammoniac concentration is increasing, then its neutralisation cost is increasing."

Typical examples of such pairwise trend relations are given in Figure 1.
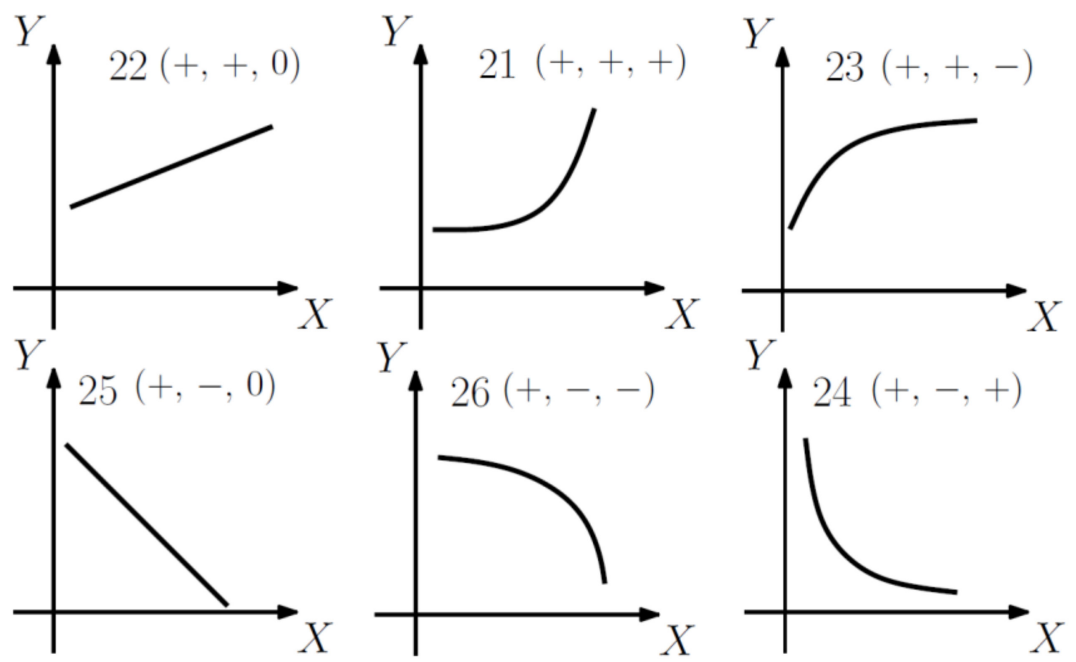

Figure 1. Example of qualitative pairwise relations.

All pairwise relations, $X$ and $Y$, in Figure 1, are trend relations, that is, increasing, constant, and decreasing. This means that nothing is quantified. The numbers 21, 22 and 23 (Figure 1) are just identifications of pairwise relations for the first coordinate system quadrant. Similarly, pairwise relations can be defined for the other coordinate system quadrants. For example, the relation of number 21 (Figure 1) indicates the following:

- The relation is increasing, the first derivative is therefore positive.

- The increase is more and more rapid, that is, the second derivative is therefore positive.

- If $X=0$, then $Y=$ positive.

\section{Materials and Methods}

Qualitative reasoning is a part of these new trends in the analysis of complex and vague tasks, (see, e.g., [16]). Common sense reasoning algorithms, for example, qualitative reasoning, will be accepted by 
users from industry, business, and so on, if they are simple. However, qualitative algorithms are not simple. This means that a high-quality user-friendly interface is essential (see, e.g., [29,31]). These problems are not studied in this paper (for details, see, e.g., [32]).

\subsection{Qualitative Models}

Qualitative models are based just on the four quantifiers from Table 1 (see, e.g., [11]).

Table 1. The quantifiers.

\begin{tabular}{ccccc}
\hline Values: & Positive & Zero & Negative & Anything \\
\hline Derivatives: & Increasing & Constant & Decreasing & Any direction \\
Symbol: & + & 0 & - & $*$ \\
\hline
\end{tabular}

A set of $m$ qualitative $n$-dimensional scenarios is described by the following sets of triplets:

$$
\mathbf{S}=\left\{\left[\left(X_{1}, \mathrm{DX}_{1}, \mathrm{DDX}_{1}\right),\left(X_{2}, \mathrm{DX}_{2}, \mathrm{DDX}_{2}\right), \ldots,\left(X_{n}, \mathrm{DX}_{n}, \mathrm{DDX}_{n}\right)\right]_{j}\right\}, j=1,2, \ldots, m
$$

where $X_{i}$ is the $i$-th variable, and $\mathrm{D} X_{i}$ and $\mathrm{DDX} X_{i}$ are the first qualitative and the second qualitative derivations, respectively, with respect to time $t$.

An important aspect of sustainability models is the quantification of specific variables, namely (see [33]):

- Contributing to a better understanding of the meaning of sustainability and its contextual interpretation (interpretation challenge);

- Integrating sustainability issues into decision-making by identifying and assessing (past and/or future) sustainability impacts (information-structuring challenge); and

- Fostering sustainability objectives (influence challenge).

Over the last two decades, there have been plenty sustainability indicators (SI).

Similar problems to those of the SIs are solved in, for example, purely ecological tasks (see ecological indicators, e.g., [24]).

There are only second derivatives, DD, in Model (2). It is possible to introduce higher qualitative derivatives into sustainability and related models. However, the network of available knowledge items is often so poor, inconsistent, and sparse, that the higher derivatives are not known. It is not an exceptional problem that even the first derivatives are not predictable. Therefore, just the second derivatives are studied in this paper.

An equation-less qualitative model is a set of $w$ pairwise relations, as follows:

$$
\mathrm{P}_{s}\left(X_{i}, X_{j}\right), s=1,2, \ldots, w
$$

There are just four qualitative values (Table 1). The set of scenarios in Model (2) are therefore discrete and final. It is a combinatorial task to solve Model (3). This problem is not studied in this paper. An introduction into the methodology of qualitative models and their solutions is given, for example, by the authors of [11,12].

If the second derivatives are not known, then the relations, P, of Model (3) can be simplified as follows:

$$
\begin{aligned}
& \text { If } X_{1} \text { is increasing, then } X_{2} \text { is increasing. } \\
& \text { If } X_{1} \text { is decreasing, then } X_{2} \text { is decreasing. } \\
& \text { If } X_{3} \text { is increasing, then } X_{2} \text { is decreasing. } \\
& \text { If } X_{3} \text { is decreasing, then } X_{2} \text { is increasing. }
\end{aligned}
$$


The relation in Model (4) is described by the following set of two relations:

$$
\begin{array}{ll}
\mathrm{QP}+ & \mathrm{X}_{1} \mathrm{X}_{2} \\
\mathrm{QP}- & \mathrm{X}_{3} \mathrm{X}_{2}
\end{array}
$$

where the following is true:

$\mathrm{QP}+$ qualitative direct proportionality,

$\mathrm{QP}-$ qualitative indirect proportionality.

$\mathrm{QP}+$ covers all three of the increasing shapes of numbers 21, 22 and 23 (in Figure 1). QP - covers all three of the decreasing shapes of numbers 24,25 and 26 (in Figure 1).

The qualitative proportionalities $(\mathrm{QP})$ are the lowest information intensive knowledge items. If it is not possible to relate these two variables by a qualitative proportionality, then nothing is known about these pairwise relations.

The following set of two relations is used to demonstrate the results of a simple qualitative model:

$$
\begin{array}{cccc}
\text { Shape } & X & Y \text { (see Figure 1) } \\
1 & 22 \text { (see Figure 1) } & X_{1} & X_{2} \\
2 & 26 \text { (see Figure 1) } & X_{3} & X_{2}
\end{array}
$$

There are 17 qualitative scenarios as the possible solution for Model (6), $m=17$ using Model (3) (see, e.g., $[11,12])$, as follows:

\begin{tabular}{cccc}
\hline & $X_{1}$ & $X_{2}$ & $X_{3}$ \\
\hline 1 & +++ & +++ & +-- \\
2 & ++0 & +++ & +-- \\
3 & ++- & +++ & +-- \\
4 & ++- & ++0 & +-- \\
5 & ++- & ++- & +-+ \\
6 & ++- & ++- & +-0 \\
7 & ++- & ++- & +-- \\
8 & $+0+$ & $+0+$ & $+0-$ \\
9 & +00 & +00 & +00 \\
10 & $+0-$ & $+0-$ & $+0+$ \\
11 & +-+ & +-+ & ++- \\
12 & +-0 & +-+ & ++- \\
13 & +-- & +-+ & ++- \\
14 & +-- & +-0 & ++- \\
15 & +-- & +-- & +++ \\
16 & +-- & +-- & ++0 \\
17 & +-- & +-- & ++- \\
\hline
\end{tabular}

The qualitative description of variable $X_{3}$ of the first scenario, $S_{1}$, is represented by the triplet $(+--)$. It means that $X_{3}=+$; for example, it is a concentration and is, by its very nature, always positive. For $\mathrm{DX}_{3}=-$, see Model (2), the first time derivative is negative; this means that the concentration is decreasing. For $\mathrm{DDX}_{3}=-$, see Model (3), the second time derivative is negative and the decrease is more and more rapid. 


\subsection{Transitional Graph}

The set of scenarios $\mathbf{S}$ from Model (2) is not the only result of qualitative modeling. It is possible to generate transitions among the set of scenarios. A complete set of all of the possible one-dimensional transitions is given in Table 2.

Table 2. A list of all of the one-dimensional transitions.

\begin{tabular}{cccccccccc}
\hline & From & & To & Or & Or & Or & Or & Or & Or \\
\hline & & & a & b & c & d & e & f & $\mathrm{g}$ \\
1 & +++ & $\rightarrow$ & ++0 & & & & & & \\
2 & ++0 & $\rightarrow$ & +++ & ++- & & & & & \\
3 & ++- & $\rightarrow$ & ++0 & $+0-$ & +00 & & & & \\
4 & $+0+$ & $\rightarrow$ & +++ & & & & & & \\
5 & +00 & $\rightarrow$ & +++ & +-- & & & & & \\
6 & $+0-$ & $\rightarrow$ & +-- & & & & & & \\
7 & +-+ & $\rightarrow$ & +-0 & $+0+$ & +00 & $0-+$ & $00+$ & 000 & $0-0$ \\
8 & +-0 & $\rightarrow$ & +-+ & +-- & $0-0$ & & & & \\
9 & +-- & $\rightarrow$ & +-0 & $0--$ & $0-0$ & & & & \\
10 & $0++$ & $\rightarrow$ & ++0 & ++- & +++ & & & & \\
11 & $0+0$ & $\rightarrow$ & ++0 & ++- & +++ & & & & \\
12 & $0+-$ & $\rightarrow$ & ++- & & & & & & \\
13 & $00+$ & $\rightarrow$ & +++ & & & & & \\
14 & 000 & $\rightarrow$ & +++ & --- & & & & & \\
15 & $00-$ & $\rightarrow$ & --- & & & & & & \\
16 & $0-+$ & $\rightarrow$ & --+ & & & & & & \\
17 & $0-0$ & $\rightarrow$ & --0 & --+ & --- & & & \\
18 & $0--$ & $\rightarrow$ & --0 & --+ & --- & & & \\
19 & -++ & $\rightarrow$ & -+0 & $0++$ & $0+0$ & & & & \\
20 & -+0 & $\rightarrow$ & -+- & -++ & $0+0$ & & & & \\
21 & -+- & $\rightarrow$ & -+0 & $-0-$ & -00 & $0+-$ & $00-$ & 000 \\
22 & $-0+$ & $\rightarrow$ & -++ & & & & & \\
23 & -00 & $\rightarrow$ & -++ & --- & & & & & \\
24 & $-0-$ & $\rightarrow$ & --- & & & & & & \\
25 & --+ & $\rightarrow$ & --0 & $-0+$ & -00 & & & & \\
26 & --0 & $\rightarrow$ & --- & --+ & & & & & \\
27 & --- & $\rightarrow$ & --0 & & & & & & \\
\hline
\end{tabular}

For example, the third line of Table 2 indicates that it is possible to transfer triplet $(++-)$ into triplet $(++0)$. This transition is not the only possible one. There are two more possible transitions. Figure 2 gives a qualitative description of an oscillation using the one-dimensional triplets $n=1$ from Model (2).

Table 2 is not a dogma. It could be modified on an ad hoc basis. The only requirement is that the transitions must satisfy the common sense feeling of the user.

A transitional graph, G, is an oriented graph. Its nodes are the set of scenarios $\mathbf{S}$ from Model (2) and the oriented arcs are the transitions $\mathbf{T}$ among the scenarios $\mathbf{S}$.

$$
\mathrm{G}=(\mathbf{S}, \mathbf{T})
$$

Any oscillation can be represented by a simple oriented graph, see Figure 2. The transition from triplet $(+++)$ to triplet $(++0)$ is based on the first row of Table 2, transition 1a. 


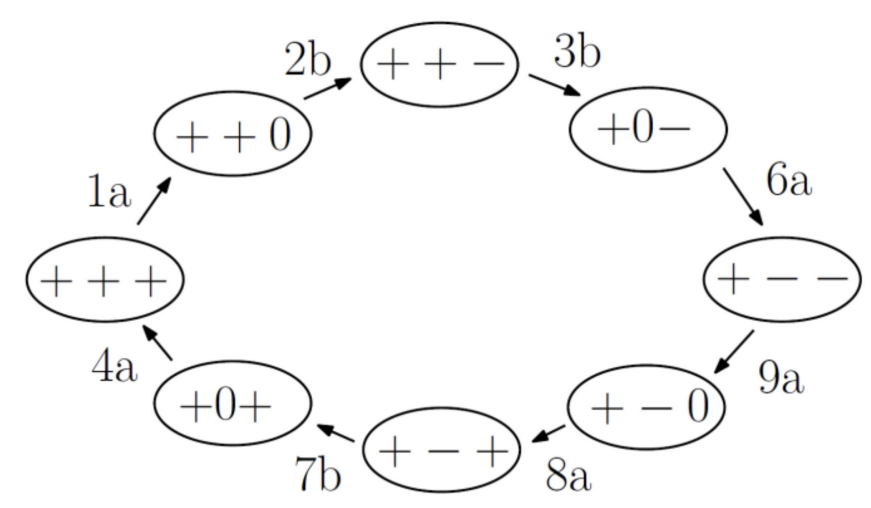

Figure 2. Transitional graph of an oscillation.

An $n$-dimensional scenario based on $n$ variables from Model (2) must be checked, using Table 2, for all of the $n$ variables. In other words, $n$ one-dimensional transitions must be feasible to transfer one n-dimensional scenario into another.

An $n$-dimensional, Model (2), is a set of $r$ equation-less relations (see, e.g., Figure 1), as follows:

$$
\mathrm{M}=(r, n)
$$

The transitional graph, Model (7), of Model (6), is given in Figure 3.

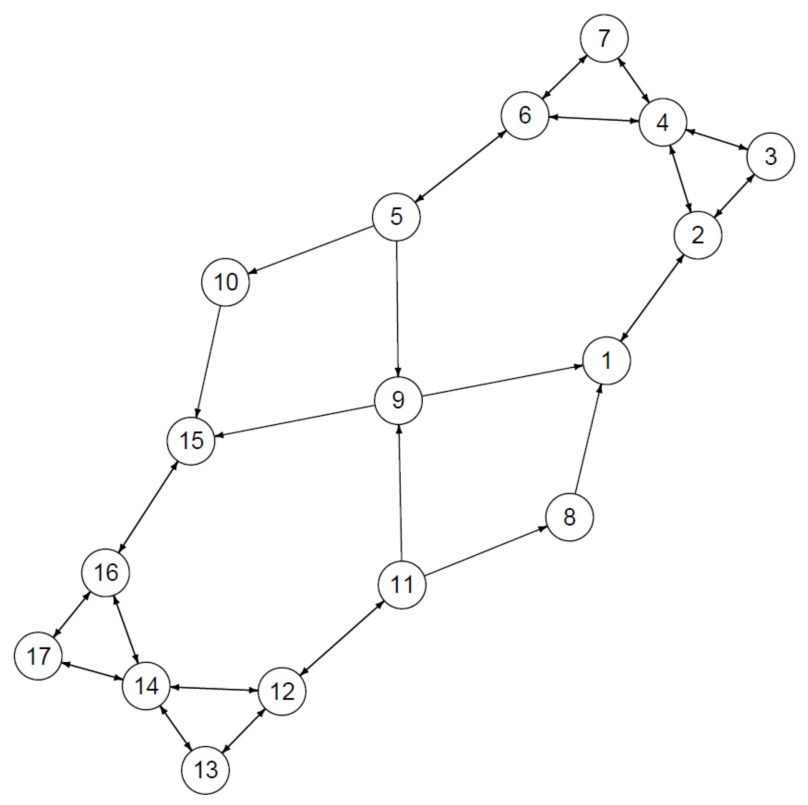

Figure 3. Tutorial example of a transitional graph.

\subsection{Sustainability Decision Making}

Decision-making tasks related to sustainable problems have been studied for many years (see, e.g., [34-36]). Specific decision trees can be generated and evaluated (e.g., a food waste management decision tree, see [37]). However, the variability of sustainability decision problems require multiple goal decision making (see, e.g., [38]). This problem is not studied in this paper.

Let us suppose that there are two independent variables, $X_{1}$ and $X_{2}$, and an objective function, $\Theta$. The objective function has to be maximized (e.g., profit). This means that the first derivative of $\Theta$ must be positive in order to guarantee an increase of $\Theta$, as follows: 
The best variant is

$$
\mathrm{D} \Theta=+, \mathrm{DD} \Theta=+.
$$

This means that the objective function is increasing more and more quickly. This is the most favorable situation to maximize $\Theta$.

Let us suppose that a sustainability model has the following set of three scenarios, $\mathbf{S},(n=3, m=3$, see Model [3]):

Therefore, the first trend scenario in Table 3 is totally wrong because the objective function, $\Theta$, decreases more and more rapidly, see $(+--)$ in Table 3 . The second scenario in Table 3 is the best one, Model (11).

Table 3. Scenarios. $X_{1}$ and $X_{2}$-independent variables; $\Theta$-objective function.

\begin{tabular}{cccc}
\hline & $X_{1}$ & $X_{2}$ & $\Theta$ \\
\hline 1 & +++ & +++ & +-- \\
2 & $+0-$ & +-- & +++ \\
3 & +-- & +-+ & +-+ \\
\hline
\end{tabular}

The set of variables, $X$, Model (10), can be divided into three subsets from the point of view of optimization, as follows:

$$
\boldsymbol{X}=X_{1}, X_{2}, \ldots, X_{n}=\mathbf{D} \cup \mathbf{N} \cup \mathbf{G}
$$

A set, $\boldsymbol{X}$, of $n$ variables is a union, Model (10), of variables under (managerial) control, D, non-controllable variables, $\mathbf{N}$, and the single goal variable, $\mathbf{G}$.

The model, $\mathrm{M}$, used in this paper is simplified, as follows:

$$
M=f(X)=f(D, N, G)
$$

All non-controllable variables, $\mathbf{N}$, are expressed as follows:

$$
\mathbf{N}=\mathrm{f}(\mathbf{C}, \mathbf{G}) \text {. }
$$

The relation, Model (12), is based on the assumption that a reaction of the opponent(s) is predictable. If, for example, taxation is a non-controllable variable, then a government does not use a stochastic generator to develop its taxation strategy. The government decisions are based on carefully studied relations among the complete set of variables, $X$, and the relation, Model (12), can be incorporated into the model, $\mathrm{M}$, Model (11).

However, if an $\mathbf{N}$ variable has a stochastic nature (e.g., weather predictions), then it is possible to develop a conventional decision tree (see, e.g., [39]). One has to keep in mind that a decision, that is, a quantification of all (some) of the variables, $\mathrm{D}$, is made prior to any stochastic generation of the $\mathbf{N}$ variables. For example, an invest decision, $\mathrm{D}$, is done before the knowledge of the new taxation policy is known.

This paper presents the case study, given below, using Equation (12). It means that any stochasticity is eliminated.

\subsection{Qualitative Trees Generated From Transition Graphs}

A transitional graph represents all of the possible future behaviours of a sustainability system under study. A decision maker can generate a (decision) tree using his/her (semi) subjective preferences. The root of the tree is, for example, a current situation of the system. An example of such a tree is given in Figure 4, and is based on the oriented graph in Figure 3. Tutorial example of a transitional graph, the root scenario, is the scenario of number 5 in Figure 4. 


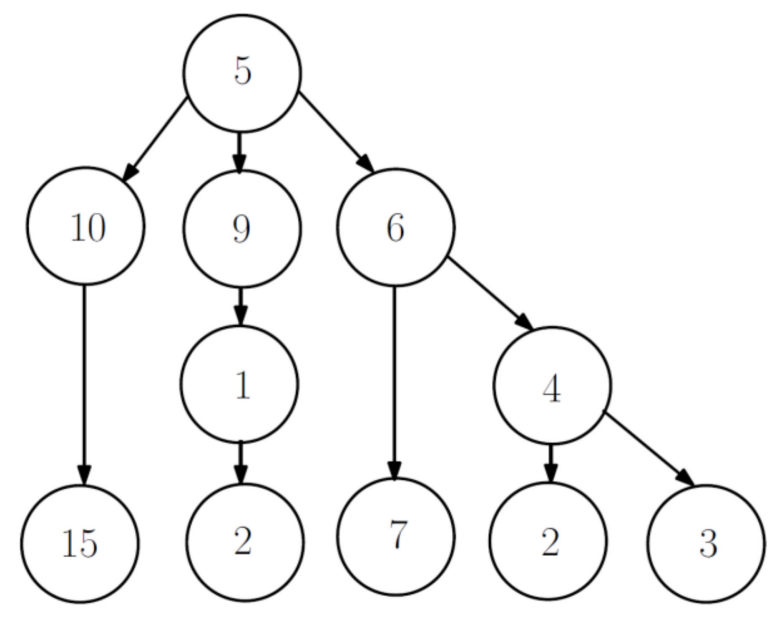

Figure 4. Qualitative Tree.

\subsection{Quantitative Evaluations of Qualitative Trees-Reconciliation}

There is a spectrum of different trees used for decision making (see, e.g., [40]). Decision tasks can be represented by single root trees (see, e.g., [41]) and sets of available input information items (III), for example, probabilities, penalties, and so on (see, e.g., [42,43]). The complete III set is usually not available (see, e.g., [44,45]).

An algorithm is needed to quantify the missing values of an incomplete set of III. This problem is described by Doubravsky and Dohnal [46] as metaheuristics, drawing a strong analogy between the water flow through a one root tree system of pipes and the decision tree of the same topology. This analogy is based on the assumption/metaheuristics (see, e.g., [46,47]), as follows.

Hypothesis 1 (H1). The longer the path, the less probable the path is.

Let us imagine a situation where decision makers have incomplete information about the decision-making problem/task. There are three variants, as follows:

- Complete III, i.e., all of the numerical values needed to evaluate the decision tree using traditional algorithms are available;

- Total ignorance, not a single numerical value is available; and

- Partial ignorance, some numerical values are available.

If complete III is available, then the well-known algorithm is used in this paper (see, e.g., [48]).

The corresponding decision-making problem is solved under total ignorance if only the topology of the decision tree under study is known (see, e.g., [46]). A decision-making problem under total ignorance gives a system of linear equations, $\mathbf{A} \cdot \mathbf{P}=\mathbf{B}$, where the set, $\mathbf{P}$, is a vector of unknown variables (e.g., probabilities, penalties, etc.), $\mathbf{A}$ is the set of splitting ratios of the decision tree, and $\mathbf{B}$ is a vector of numerical constants based on the balance equations (for details, see, e.g., [46,49]).

The total ignorance is transferred into the partial ignorance if some isolated elements of III are available, for example, probabilities and penalties (see, e.g., [49]). An incomplete set of isolated specific probabilities, as follows:

$$
\mathrm{R} \equiv\left(\mathrm{R}_{1}, \mathrm{R}_{2}, \ldots, \mathrm{R}_{h}\right) .
$$

has $h$ elements. Each element of the set, R, can be formally interpreted as an equation.

The concept of the total ignorance represented by metaheuristics, H1, allows us to incorporate a set of isolated specific information items within a general framework of the metaheuristic (see, e.g., [46]). The answer to the question of how to incorporate additional information into total ignorance gives the following description of a reconciliation algorithm. 
The problems of reconciliation are very important and have been studied for more than 30 years (see, e.g., [50]). Reconciliation is a solution of an over-specified set of linear equations, as follows:

$$
\mathbf{A} \cdot \mathbf{P}=\mathbf{B} \cup \mathbf{P}=\mathbf{R} .
$$

The set of equations has $n+h$ equations and $n$ variables, $\mathbf{P}$. The set of equations in Model (14) nearly always has no solution. A suitable objective function $Q$, as follows:

$$
Q=\sum_{j=1}^{h} d_{j}
$$

is minimized. This function, Model (15), is usually the sum of deviations, $d$, Model (16), as follows:

$$
d_{j}=P_{j}-R_{j}
$$

where $j=1, \ldots, h$. A method of linear programming is used to solve the following problems, Model (17):

$$
\begin{gathered}
\min Q \\
a_{1} P_{1}=b_{1} \\
\vdots \\
a_{n} P_{n}=b_{n} \\
P_{n+1}=R_{n+1} \\
\vdots \\
P_{n+h}=R_{n+h}
\end{gathered}
$$

Numbers are absolutely precise and thus do not reflect the inherent lack of precision or vagueness of realistic sustainability knowledge. Similar difficulties are typical for nearly all of the branches of science and engineering. This fact has been taken into account by relatively extensive applications of different branches of probability theory. However, the only objective way to evaluate the probability of an event is to repeat the measurement/observation of an outcome of an event infinitely many times under the same conditions. As this is practically impossible, the subjective quantification of different types of vagueness has been introduced.

Fuzzy logic is a vague formal tool that is based on a concept of fuzzy sets and a grade of membership (see Figure 5). For details, see [50,51].

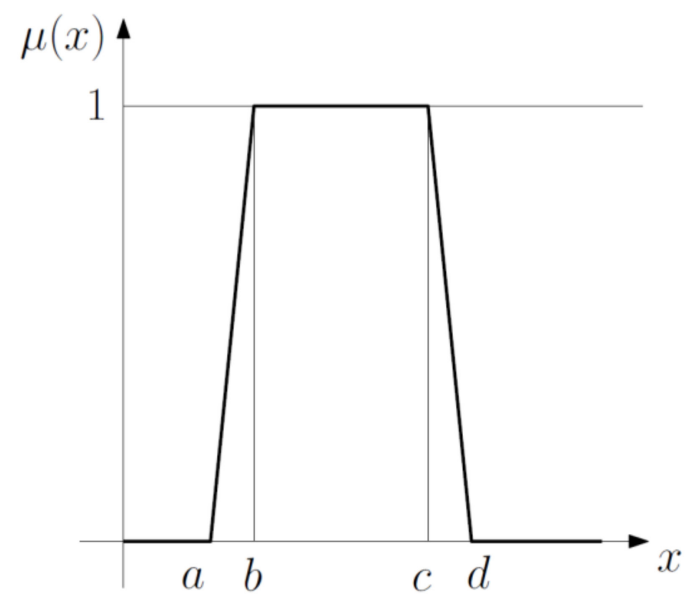

Figure 5. Rectangular grade of membership. 


\section{Case Study}

This paper is based on the following set of decision, $\mathbf{D}$, and lottery, $\mathbf{N}$, variables (see Tables 4 and 5) [23], as follows.

Table 4. Decision variables (D) (under managerial control).

\begin{tabular}{cc}
\hline Variable & Label \\
\hline Cash Flow & $C F$ \\
Return on Assets & $R O A$ \\
Value Added & $V A$ \\
Earnings after taxes & $E A T$ \\
Ecology related investments & $E R I$ \\
Consumption of renewable energy & $C R E$ \\
Production of waste & $P W$ \\
Productivity of labour & $P L$ \\
Corporate governance & $C G$ \\
\hline
\end{tabular}

Table 5. Lotteries (N) (outside managerial control).

\begin{tabular}{cc}
\hline Variable & Label \\
\hline Sustainability Political Will & SPW \\
Taxes & $T A$ \\
\hline
\end{tabular}

It is clear that the interpretation of the variables (Tables 4 and 5) depends on the point of view, and is (partially) subjective. For example, the variable of taxes (TA) is a lottery if the decision maker is a manager and not a relevant government. The cash flow $(C F)$ is, in theory, under managerial control, however, it can be outside the managerial control if some mistakes are made.

The following set of 12 pairwise relations, Model (3), is used:

\begin{tabular}{cccc} 
No. & \multicolumn{4}{c}{ (see Figure 1) } & $X$ & $Y$ \\
& (see Model [7]) & \\
1 & $\mathrm{QP}+$ & $R O A$ & $V A$ \\
2 & $\mathrm{QP}-$ & $C F$ & $C G$ \\
3 & 22 & $P L$ & $V A$ \\
4 & $\mathrm{QP}-$ & $E A T$ & $\mathrm{TA}$ \\
5 & $\mathrm{QP}+$ & $C G$ & $E R I$ \\
6 & 24 & $S P W$ & $P W$ \\
7 & 23 & $S P W$ & $C R E$ \\
8 & 24 & $S P W$ & TA \\
9 & 21 & $C F$ & $E R I$ \\
10 & $\mathrm{QP}-$ & $P L$ & $P W$ \\
11 & 24 & $E R I$ & $C R E$ \\
12 & $\mathrm{QP}-$ & $S P W$ & $E R I$
\end{tabular}

The first step is to only evaluate the first derivatives. There are three scenarios based on the first derivatives if Model (18) is solved, see Table 6.

Table 6. Scenarios.

\begin{tabular}{|c|c|c|c|c|c|c|c|c|c|c|c|}
\hline & $P L$ & $V A$ & $R O A$ & $C R E$ & $C F$ & $P W$ & $E A T$ & $T A$ & $C G$ & $S P W$ & $E R I$ \\
\hline 1 & $++^{*}$ & $++^{*}$ & $++^{*}$ & $++^{*}$ & $+-*$ & $+-^{*}$ & $++^{*}$ & $+-{ }^{*}$ & $+-*$ & $++^{*}$ & $+-^{*}$ \\
\hline 2 & $+0^{*}$ & $+0^{*}$ & $+0^{*}$ & $+0 *$ & $+0^{*}$ & $+0^{*}$ & $+0^{*}$ & $+0 *$ & $+0^{*}$ & $+0 *$ & +0 * \\
\hline 3 & $+-*$ & $+-^{*}$ & $+-^{*}$ & $+-*$ & $++^{*}$ & $++^{*}$ & $+-^{*}$ & $++^{*}$ & $++^{*}$ & $+-^{*}$ & $++^{*}$ \\
\hline
\end{tabular}

Where * indicates any value (Table 1 ) of the second derivative from Model (2). 
It is clear that the second scenario (see Table 6) is the steady state, that is, no changes. The first scenario (Table 6) represents a situation when the following variables are increasing, as they have the positive first derivative: productivity of labour (PL), value added (VA), return on assets (ROA), consumption of renewable energy (CRE), EAT, and sustainability political will (SPW) (Tables 4 and 5). A simple common sense analysis indicates preferences for all of the variables (see Table 7). The very nature of the variables of production of waste (PW) and taxes (TA) requires their decreases.

Table 7. Required changes of variables (i.e., preferences).

\begin{tabular}{ccccccccccc}
\hline$P L$ & $V A$ & $R O A$ & $C R E$ & $C F$ & $P W$ & $E A T$ & $T A$ & $C G$ & $S P W$ & $E R I$ \\
\hline$\uparrow$ & $\uparrow$ & $\uparrow$ & $\uparrow$ & $\uparrow$ & $\downarrow$ & $\uparrow$ & $\downarrow$ & $\uparrow$ & $\uparrow$ & $\uparrow$ \\
\hline
\end{tabular}

The second step is to solve Model (18), taking the second derivatives into consideration. Model (18) gives the set of 27 scenarios (see Table 8). The following auxiliary variables, $\mathrm{O}_{i}$, for $i=1,2, \ldots, m$ (see Model (2)), are based on the set of scenarios from Table 8 .

Table 8. Scenarios.

\begin{tabular}{|c|c|c|c|c|c|c|c|c|c|c|c|}
\hline & $P L$ & $V A$ & $R O A$ & $C R E$ & $C F$ & $P W$ & $E A T$ & $T A$ & $C G$ & $S P W$ & ERI \\
\hline 1 & +++ & +++ & +++ & +++ & +-- & +-- & +++ & +-- & +-- & +++ & +-- \\
\hline 2 & +++ & +++ & +++ & +++ & +-- & +-- & ++0 & +-0 & +-- & +++ & +-- \\
\hline 3 & +++ & +++ & +++ & +++ & +-- & +-- & ++- & +-+ & +-- & +++ & +-- \\
\hline 4 & ++0 & ++0 & ++0 & +++ & +-- & +-0 & +++ & +-- & +-- & +++ & +-- \\
\hline 5 & ++0 & ++0 & ++0 & +++ & +-- & +-0 & ++0 & +-0 & +-- & +++ & +-- \\
\hline 6 & ++0 & ++0 & ++0 & +++ & +-- & +-0 & ++- & +-+ & +-- & +++ & +-- \\
\hline 7 & ++- & ++- & ++- & +++ & +-- & +-+ & +++ & +-- & +-- & +++ & +-- \\
\hline 8 & ++- & ++- & ++- & +++ & +-- & +-+ & ++0 & +-0 & +-- & +++ & +-- \\
\hline 9 & ++- & ++- & ++- & +++ & +-- & +-+ & ++- & +-+ & +-- & +++ & +-- \\
\hline 10 & ++- & ++- & ++- & ++- & +-+ & +-+ & ++- & +-+ & +-+ & ++- & +-+ \\
\hline 11 & ++- & ++- & ++- & ++- & +-0 & +-+ & ++- & +-+ & +-+ & ++- & +-+ \\
\hline 12 & ++- & ++- & ++- & ++- & +-- & +-+ & ++- & +-+ & +-+ & ++- & +-+ \\
\hline 13 & $+0+$ & $+0+$ & $+0+$ & $+0+$ & $+0-$ & $+0-$ & $+0+$ & $+0-$ & $+0-$ & $+0+$ & $+0-$ \\
\hline 14 & +00 & +00 & +00 & +00 & +00 & +00 & +00 & +00 & +00 & +00 & +00 \\
\hline 15 & $+0-$ & $+0-$ & $+0-$ & $+0-$ & $+0+$ & $+0+$ & $+0-$ & $+0+$ & $+0+$ & $+0-$ & $+0+$ \\
\hline 16 & +-+ & +-+ & +-+ & +-+ & ++- & ++- & +-+ & ++- & ++- & +-+ & ++- \\
\hline 17 & +-+ & +-+ & +-+ & +-+ & ++- & ++- & +-0 & ++0 & ++- & +-+ & ++- \\
\hline 18 & +-+ & +-+ & +-+ & +-+ & ++- & ++- & +-- & +++ & ++- & +-+ & ++- \\
\hline 19 & +-0 & +-0 & +-0 & +-+ & ++- & ++0 & +-+ & ++- & ++- & +-+ & ++- \\
\hline 20 & +-0 & +-0 & +-0 & +-+ & ++- & ++0 & +-0 & ++0 & ++- & +-+ & ++- \\
\hline 21 & +-0 & +-0 & +-0 & +-+ & ++- & ++0 & +-- & +++ & ++- & +-+ & ++- \\
\hline 22 & +-- & +-- & +-- & +-+ & ++- & +++ & +-+ & ++- & ++- & +-+ & ++- \\
\hline 23 & +-- & +-- & +-- & +-+ & ++- & +++ & +-0 & ++0 & ++- & +-+ & ++- \\
\hline 24 & +-- & +-- & +-- & +-+ & ++- & +++ & +-- & +++ & ++- & +-+ & ++- \\
\hline 25 & +-- & +-- & +-- & +-- & +++ & +++ & +-- & +++ & +++ & +-- & +++ \\
\hline 26 & +-- & +-- & +-- & +-- & ++0 & +++ & +-- & +++ & +++ & +-- & +++ \\
\hline 27 & +-- & +-- & +-- & +-- & ++- & +++ & +-- & +++ & +++ & +-- & +++ \\
\hline
\end{tabular}

$$
\mathrm{O}_{i}=\text { number of feasible (see Table 7) first derivatives }
$$

where $i$ is the number of the corresponding scenario. The number of feasible first derivatives, $\mathrm{O}_{1}$, according to Table 7 , of the first scenario of Table 8 is 8 .

There are 97 transitions, $\mathbf{T}$, Model (7), among the set of 27 scenarios (see Table 8). The corresponding transitional graph, G, Model (7), is given in Figure 6. 


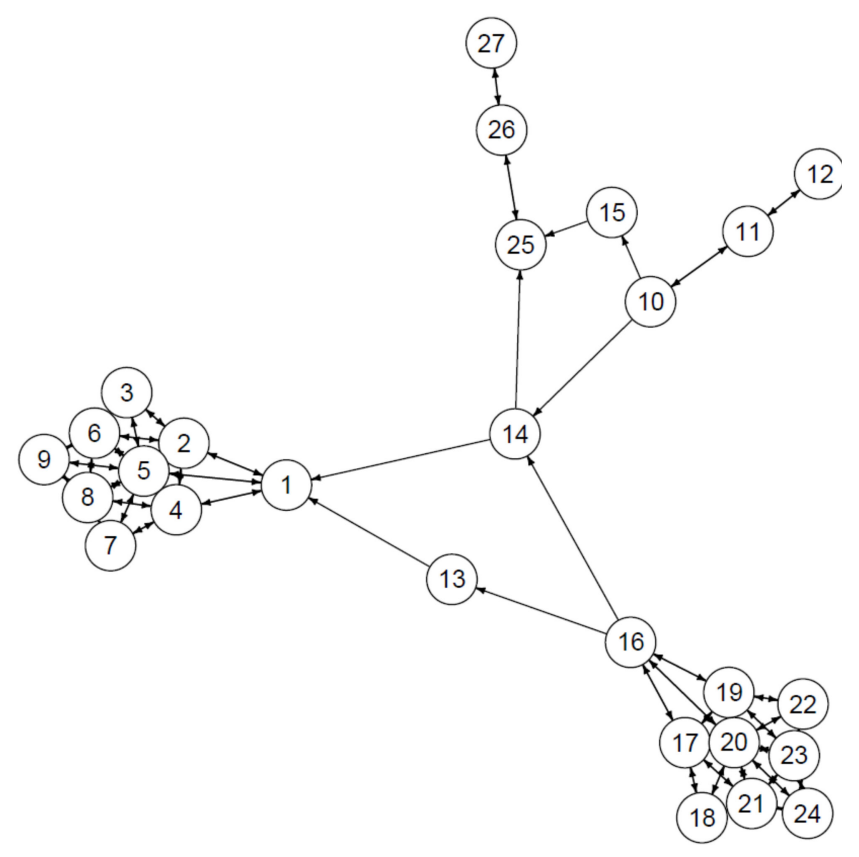

Figure 6. Transitional graph between the scenarios from Table 4.

Let us suppose that the current situation under study corresponds to scenario number 14 of Figure 6 and Table 8 and that the following qualitative tree of Figure 7 is relevant to a decision maker. This means, that the tree is (partially) subjectively chosen by the decision makers, taking into consideration some of subjective preferences, and reflects their interests. In other words, the following decision tree is not the only variant. It is therefore highly desirable to study several decision trees.

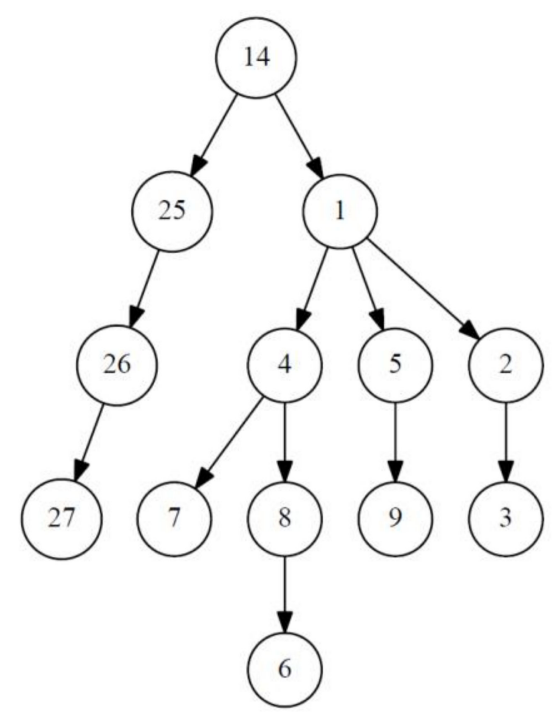

Figure 7. Qualitative tree.

The scenarios of numbers 3, 6, 7, 9 and 27 are terminals of the qualitative tree. Each terminal scenario has its utility, that is, a level of satisfaction of the preferences, see Table 7 . The utility, $u$, is calculated as the ratio of a number of variables, $u_{i}=\mathrm{O}_{i} / n$, see (19), where $i$ is the number of the corresponding scenario.

The list of utilities of all of the terminals is as follows. 
For example, the terminal of number 27 has its utility as 0.272 (see Table 9). The number of variables satisfying Table 7 is 3 (CF, CG, ERI); there are 11 variables (see Tables 4 and 5). The utility is calculated as $3 / 11=0.272$.

Table 9. Utility of terminals.

\begin{tabular}{cc}
\hline $\begin{array}{c}\text { Scenario } \boldsymbol{i} \\
\text { (See Figure 7) }\end{array}$ & Utility $\boldsymbol{u}_{\boldsymbol{i}}$ \\
\hline 3 & 0.727 \\
6 & 0.727 \\
7 & 0.727 \\
9 & 0.727 \\
27 & 0.272 \\
\hline
\end{tabular}

\section{Results}

The heuristic, H1, is used to evaluate the qualitative tree (see Figure 7). The total ignorance problem has the solution given in Table 9.

A common sense interpretation of the heuristic, H1, indicates that the shortest branch, that is, the transfer scenario $14 \rightarrow 25$ of the qualitative tree, see Figure 7, has the dominant probability.

A partial ignorance problem means that some probabilities are vaguely known by the decision makers and are specified as fuzzy sets. Four fuzzy sets are given by a decision maker in Table 10 (see Figure 5).

Table 10. Fuzzy sets.

\begin{tabular}{ccccc}
\hline Transition from $\boldsymbol{i}$ to $\boldsymbol{j}$ & \multicolumn{3}{c}{ Fuzzy } & Probability \\
\hline$i$ & $j$ & $a$ & $b=c$ & $d$ \\
1 & 5 & 0.5 & 0.6 & 0.65 \\
1 & 4 & 0.25 & 0.3 & 0.4 \\
14 & 25 & 0.6 & 0.7 & 0.8 \\
14 & 1 & 0.35 & 0.4 & 0.45 \\
\hline
\end{tabular}

The probabilities of the remaining transitions are not given. This means that the general heuristic, H1, must be reconciled with the fuzzy sets given in Table 10. The reconciliation result is given in Table 11.

Table 11. Probabilities of transfers evaluated by the heuristic-partial ignorance case.

\begin{tabular}{ccc}
\hline Transition from Scenario $\boldsymbol{i}$ to Scenario $\boldsymbol{j}$ (See Figure 7$)$ & Probability of Transition \\
\hline $\boldsymbol{i}$ & $\boldsymbol{j}$ & $\boldsymbol{P}$ \\
\hline 14 & 25 & 0.6 \\
14 & 1 & 0.4 \\
25 & 26 & 1 \\
26 & 27 & 1 \\
1 & 4 & 0.3 \\
1 & 5 & 0.5 \\
1 & 2 & 0.2 \\
4 & 7 & 0.667 \\
4 & 8 & 0.333 \\
5 & 9 & 1 \\
2 & 3 & 1 \\
8 & 6 & 1 \\
\hline
\end{tabular}

Values of $u_{i} \cdot P_{i}$ (see Table 12) indicate the preferences (see Table 7) of all of the terminals and their probability (see Table 12). The highest value has the terminal of number 27 . The only path leading 
from the root of number 14 to the terminal of number 27 is $14 \rightarrow 25 \rightarrow 26 \rightarrow 27$ (see Figure 7). This path is a trend description of a forecast or a history.

Table 12. Probabilities of terminals and the expected value.

\begin{tabular}{cccc}
\hline Terminal & Utility & Probability & \multirow{2}{*}{$\boldsymbol{u}_{\boldsymbol{i}} \cdot \boldsymbol{P}_{\boldsymbol{i}}$} \\
\cline { 1 - 3 } $\mathbf{i}$ & $\mathbf{u}_{\mathbf{i}}$ & $\mathbf{P}_{\mathbf{i}}$ & \\
\cline { 1 - 3 } 3 & 0.727 & 0.08 & 0.058 \\
6 & 0.727 & 0.04 & 0.029 \\
7 & 0.727 & 0.08 & 0.058 \\
9 & 0.727 & 0.2 & 0.145 \\
27 & 0.272 & 0.6 & 0.163 \\
\hline
\end{tabular}

There are 11 variables (see Tables 4 and 5). It is therefore not possible to present all of them. Therefore, just the non-controllable variables (SPW and TA) will be studied.

Figure 8 does not represent a conventional graph, it is a trend graph. It means that the only restrictions are the following inequalities:

$$
0<a<b<c .
$$

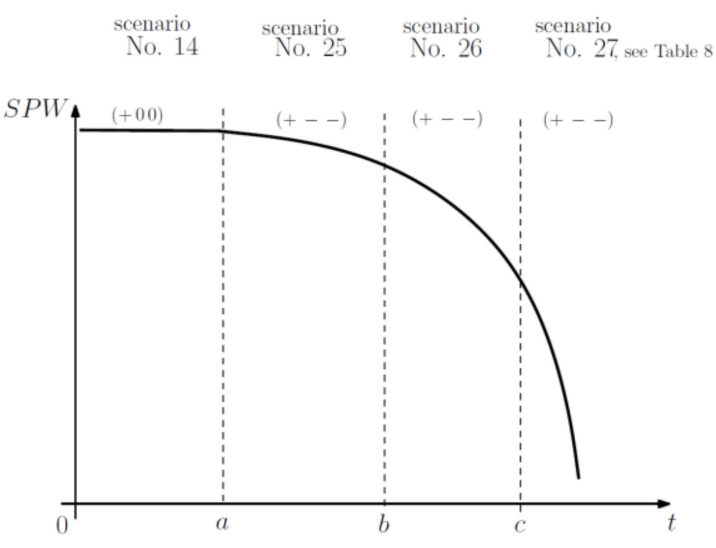

(a) $S P W(t)$

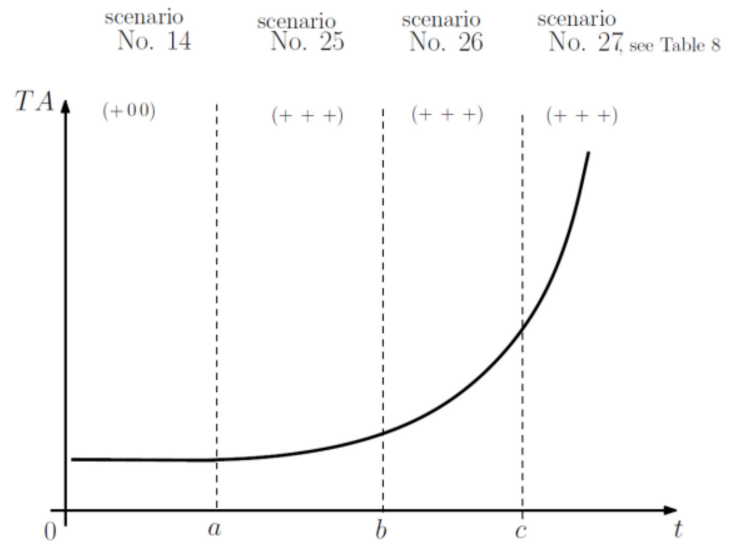

(b) $T A(t)$

Figure 8. Trend description of the functions sustainability political will $(S P W)(t)$ and taxes $(T A)(t)$.

The numerical values of the intervals, for example, the interval $(b-c)$, are irrelevant. The triplets (see the top of Figure 8) indicate the relevant trend-based shape (see Figure 1). For example, the triplet $(+--)$ represents an increase of a decrease. It means that Figure 8 is a trend shape that represents an infinite amount of traditional graphs.

\section{Discussion}

The relations among the different sustainability tasks and managements are studied extensively. There is also relatively little evidence regarding how the social capital and cognition of individual managers interacts. This means that the presented trend algorithm must be used for real complex tasks to demonstrated the flexibility of the solved sustainability tasks.

The management must keep in mind the interdisciplinary nature of the overwhelming majority of sustainability tasks. Soft sciences such as sociology, political theory, and sociology must be used. The relations among the different sustainability tasks and managements are studied extensively. There is 
also relatively little evidence regarding how the social capital and cognition of individual managers interacts. Moreover, management is under pressure to use a broad spectrum of mathematical tools.

Environmental economics and/or management (EEM) complex models of interdisciplinary natures are often interrelated mixtures of verbal descriptions based on natural languages (NL) as well as some sub-models based on classical methods of numerical mathematics, operational research, and so on. Such (semi)subjective knowledge items cannot be treated by numerical mathematics and/or statistics. Conventional statistical methods, which are directly or indirectly related to the basic law of large numbers, are difficult or impossible to apply if the studied EEM tasks are unique and complex (see [39]).

It is therefore important to identify the subjective and objective knowledge items. Dominantly objective EEM knowledge items are suitable for mathematical treatment, as follows:

- Mathematical models, sets of differential and/or algebraic equations,

- numerical/fuzzy, and so on, values of constants are not available.

- With numerical values of constants,

- statistical models, for example, an exponential function such as the least squares algorithm.

Dominantly subjective knowledge items are directly based on NLs, as follows:

- Experience,

- Analogy,

- Feelings.

Knowledge items of different levels of subjectivity based on different quantifiers (numbers, fuzzy and rough sets, etc.) must be taken into consideration to develop the best possible model of a unique complex EEM task under study. This is the reason information non-intensive formal tools are used more and more frequently (see, e.g., naïve physics algorithms, and $[7,11]$ ).

NL processing algorithms can teach computers to use NLs like human experts if some specific tasks are performed, for example, information searching and language translation. However, such NL related algorithms are far from using common sense reasoning in a way that is comparable to the human EEM analysis of NL based information.

There is an extensive body of knowledge items that have been formalized for human-readability using NLs. Unfortunately, this knowledge body is predominantly human-oriented and cannot be flexibly used by computers using different types of logics and reasoning algorithms. There is a surprisingly long history of this type of research (see, e.g., [7,11,12]), and a quickly increasing probability of successful EEM applications. This means that the EEM researcher must carefully study research developments within the artificial intelligence area.

\section{Conclusions}

Presently, most of the techniques employed for the analysis of a broad spectrum of EEM problems possess statistical natures. Unfortunately, these precise mathematical tools do not always contribute as much as is expected towards a full understanding of tasks under study.

It is no paradox that less information intensive methods of EEM analysis often achieve more realistic results in cases where the EEM system that is being modeled is very complex, and/or ill known. Modern computers are extremely powerful tools in terms of number manipulation. However, their contribution to solving vague problems, from finance and investment, using common sense, has been practically very small.

The trend models are not the final result. An optimal/feasible/not bad decision assesment must be done. Therefore, relevant decision sustainability trees are required. The trend results can be used to generate those trees. The generated trend trees can be fairly complex. It usually means that the mentioned data sets are not complete. 
All sorts of statistical analyses are used to generate EEM models. However, the mathematical forms of these knowledge items are dictated, not by reasoning or by the very nature of the problem under study, but by the statistical theories and, quite often, by tradition and rigid applications of statistical packages.

If there is no scenario, $m=0$, then the model itself is not consistent. The qualitative EEM models can be used to test the consistency. The consistency represents a very important obstacle, which must be eliminated to achieve a meaningful qualitative EEM model.

The proposed concept has been applied to several EEM problems. This is, however, not enough to believe that the methodology presented above can be used to analyse all types of complex EEM problems. A possible explanation of the success, which the qualitative method has enjoined, is that it has generated good questions for the decision-makers. The scenario generator is a useful generator of provocative questions.

The qualitative modeling itself is very flexible. It is possible to perform any union or intersection of the different models. This is a very useful feature for the verification of models and their simplifications. This aspect is important for the development of classical quantitative models.

A reconciliation algorithm can be used to achieve a feasible decision based on trend heuristic and sparse/isolated information items/data sets.

Author Contributions: K.D.: software, formal analysis, and writing (original draft preparation); A.K.: investigation, resources, validation, and writing (original draft preparation); M.D.: conceptualization, methodology, formal analysis, and writing (original draft preparation).

Funding: Grant name: Modelling and Simulation of Sustainable Investment Decision-making, The Czech Science Foundation, No. 17-23448S.

Acknowledgments: This paper is supported by the grant No. 17-23448S, Modelling and Simulation of Sustainable Investment Decision-Making of The Czech Science Foundation.

Conflicts of Interest: The authors declare no conflict of interest.

\section{References}

1. Ness, B.; Urbel-Piirsalu, E.; Anderberg, S.; Olsson, L. Categorising tools for sustainability assessment. Ecol. Econ. 2007, 60, 498-508. [CrossRef]

2. Bányai, T. Supply chain optimization of outsourced blending technologies. J. Appl. Econ. Sci. 2017, 12, 960-976.

3. Bányai, T.; Veres, P.; Illés, B. Heuristic Supply Chain Optimization of Networked Maintenance Companies. Procedia Eng. 2015, 100, 46-55. [CrossRef]

4. Li, Z.; Xu, Y.; Deng, F.; Liang, X. Impacts of Power Structure on Sustainable Supply Chain Management. Sustainability 2017, 10, 55. [CrossRef]

5. Bommier, A.; Lanz, B.; Zuber, S. Models-as-usual for unusual risks? On the value of catastrophic climate change. J. Environ. Econ. Manag. 2015, 74, 1-22. [CrossRef]

6. Allen, W.; Cruz, J.; Warburton, B. How Decision Support Systems Can Benefit from a Theory of Change Approach. Environ. Manag. 2017, 59, 956-965. [CrossRef] [PubMed]

7. Day, B.; Pinto Prades, J.-L. Ordering anomalies in choice experiments. J. Environ. Econ. Manag. 2010, 59, 271-285. [CrossRef]

8. Sen, P.K.; Singer, J.M. Large Sample Methods in Statistics: An Introduction with Applications; CRC Press: Boca Raton, FL, USA, 1994; ISBN 978-0-412-04221-8.

9. Dohnal, M.; Kocmanová, A.; Rašková, H. Hi tech microeconomics and information nonintensive calculi. Trends Econ. Manag. 2013, 2, 20-26.

10. Choueiry, B.Y.; Iwasaki, Y.; Mcllraith, S. Towards a practical theory of reformulation for reasoning about physical systems. Artif. Intell. 2005, 162, 145-204. [CrossRef]

11. Dohnal, M. A methodology for common-sense model development. Comput. Ind. 1991, 16, 141-158. [CrossRef]

12. Dohnal, M. Naive models as active expert system in bioengineering and chemical engineering. Collect. Czechoslov. Chem. Commun. 1988, 53, 1476-1499. [CrossRef] 
13. Džeroski, S.; Grbović, J.; Walley, W.J.; Kompare, B. Using machine learning techniques in the construction of models. II. Data analysis with rule induction. Ecol. Model. 1997, 95, 95-111. [CrossRef]

14. Klenk, M.; Forbus, K. Analogical model formulation for transfer learning in AP Physics. Artif. Intell. 2009, 173, 1615-1638. [CrossRef]

15. Mueller, E.T. Commonsense Reasoning; Morgan Kaufmann: Burlington, MA, USA, 2010; ISBN 978-0-08-047661-2.

16. Nayak, P.P. Causal Approximations. Artif. Intell. 1994, 70, 277-334. [CrossRef]

17. Govindan, K.; Fattahi, M.; Keyvanshokooh, E. Supply chain network design under uncertainty: A comprehensive review and future research directions. Eur. J. Oper. Res. 2017, 263, 108-141. [CrossRef]

18. Aalirezaei, A.; Aalirezaei, A. Designing Sustainable Recovery Network for Waste from Electrical and Electronic Equipment (WEEE) using Genetic Algorithm. Int. J. Environ. Sustain. Dev. 2016, 16, 60-79. [CrossRef]

19. Dehghanian, F.; Mansour, S. Designing sustainable recovery network of end-of-life products using genetic algorithm. Resour. Conserv. Recycl. 2009, 53, 559-570. [CrossRef]

20. Lipmann, O.; Bogen, H. Naive Physik Theoretische und Experimentelle Untersuchungen Über die Fähigkeit zu Intelligentem Handeln; Barth: Leipzig, Germany, 1923.

21. De Kleer, J.; Brown, J.S. A qualitative physics based on confluences. Artif. Intell. 1984, 24, 7-83. [CrossRef]

22. Dočekalová, M.P.; Kocmanová, A. Composite indicator for measuring corporate sustainability. Ecol. Indic. 2016, 61, 612-623. [CrossRef]

23. Kocmanová, A.; Pavláková Dočekalová, M.; Škapa, S.; Smolíková, L. Measuring Corporate Sustainability and Environmental, Social, and Corporate Governance Value Added. Sustainability 2016, 8, 945. [CrossRef]

24. Kratena, K.; Streicher, G. Spatial Welfare Economics versus Ecological Footprint: A Sensitivity Analysis Introducing Strong Sustainability. Environ. Resour. Econ. 2012, 51, 617-622. [CrossRef]

25. Bond, C.A.; Farzin, Y.H. Alternative sustainability criteria, externalities, and welfare in a simple agroecosystem model: A numerical analysis. Environ. Resour. Econ. 2008, 40, 383-399. [CrossRef]

26. Seghezzo, L.; Venencia, C.; Catalina Buliubasich, E.; Iribarnegaray, M.A.; Volante, J.N. Participatory, Multi-Criteria Evaluation Methods as a Means to Increase the Legitimacy and Sustainability of Land Use Planning Processes. The Case of the Chaco Region in Salta, Argentina. Environ. Manag. 2017, 59, 307-324. [CrossRef] [PubMed]

27. Banerjee, A.; Halvorsen, K.E.; Eastmond-Spencer, A.; Sweitz, S.R. Sustainable Development for Whom and How? Exploring the Gaps between Popular Discourses and Ground Reality Using the Mexican Jatropha Biodiesel Case. Environ. Manag. 2017, 59, 912-923. [CrossRef] [PubMed]

28. Bredeweg, B.; Linnebank, F.; Bouwer, A.; Liem, J. Garp3-Workbench for qualitative modelling and simulation. Ecol. Inform. 2009, 4, 263-281. [CrossRef]

29. Vicha, T.; Dohnal, M. Qualitative identification of chaotic systems behaviours. Chaos Solitons Fractals 2008, 38, 70-78. [CrossRef]

30. Forbus, K.D. Qualitative reasoning. In CRC Handbook of Computer Science and Engineering; CRC Press: Boca Raton, FL, USA, 1996.

31. Dohnal, M. Complex biofuels related scenarios generated by qualitative reasoning under severe information shortages: A review. Renew. Sustain. Energy Rev. 2016, 65, 676-684. [CrossRef]

32. Waas, T.; Hugé, J.; Block, T.; Wright, T.; Benitez-Capistros, F.; Verbruggen, A. Sustainability Assessment and Indicators: Tools in a Decision-Making Strategy for Sustainable Development. Sustainability 2014, 6, 5512-5534. [CrossRef]

33. Faucheux, S.; Froger, G. Decision-making under environmental uncertainty. Ecol. Econ. 1995, 15, $29-42$. [CrossRef]

34. Lee, S.; Lee, C.-W. Application of Decision-Tree Model to Groundwater Productivity-Potential Mapping. Sustainability 2015, 7, 13416-13432. [CrossRef]

35. Mikučionienè, R.; Martinaitis, V.; Keras, E. Evaluation of energy efficiency measures sustainability by decision tree method. Energy Build. 2014, 76, 64-71. [CrossRef]

36. Garcia-Garcia, G.; Woolley, E.; Rahimifard, S.; Colwill, J.; White, R.; Needham, L. A Methodology for Sustainable Management of Food Waste. Waste Biomass Valor 2017, 8, 2209-2227. [CrossRef]

37. Munda, G. Multiple criteria decision analysis and sustainable development. In Multiple Criteria Decision Analysis: State of the Art Surveys; International Series in Operations Research \& Management Science; Springer: New York, NY, USA, 2005; pp. 953-986. ISBN 978-0-387-23067-2. 
38. Rose, L.M. Engineering Investment Decisions: Planning Under Uncertainty; Elsevier Science Ltd.: Amsterdam, The Netherlands, 1976; ISBN 978-0-444-41522-6.

39. Burfurd, I.; Gangadharan, L.; Nemes, V. Stars and standards: Energy efficiency in rental markets. J. Environ. Econ. Manag. 2012, 64, 153-168. [CrossRef]

40. Phadatare, M.M.; Nandgaonkar, S.S. Uncertain data mining using decision tree and bagging technique. Int. J. Comput. Sci. Inf. Technol. 2014, 5, 3069-3073.

41. Butler, A.W.; Keefe, M.O.; Kieschnick, R. Robust determinants of IPO underpricing and their implications for IPO research. J. Corp. Financ. 2014, 27, 367-383. [CrossRef]

42. Zhu, H.; Zhang, C.; Li, H.; Chen, S. Information environment, market-wide sentiment and IPO initial returns: Evidence from analyst forecasts before listing. China J. Account. Res. 2015, 8, 193-211. [CrossRef]

43. Danielson, M.; Ekenberg, L.; Larsson, A. Distribution of expected utility in decision trees. Int. J. Approx. Reason. 2007, 46, 387-407. [CrossRef]

44. Nie, G.; Zhang, L.; Liu, Y.; Zheng, X.; Shi, Y. Decision analysis of data mining project based on Bayesian risk. Expert Syst. Appl. 2009, 36, 4589-4594. [CrossRef]

45. Doubravsky, K.; Dohnal, M. Reconciliation of Decision-Making Heuristics Based on Decision Trees Topologies and Incomplete Fuzzy Probabilities Sets. PLoS ONE 2015, 10, e0131590. [CrossRef] [PubMed]

46. Dohnal, M.; Vykydal, J.; Kvapilik, M.; Bures, P. Practical uncertainty assessment of reasoning paths (fault trees) under total uncertainty ignorance. J. Loss Prev. Process Ind. 1992, 5, 125-131. [CrossRef]

47. Klüppelberg, C.; Straub, D.; Welpe, I.M. (Eds.) Risk—A Multidisciplinary Introduction; Springer: Cham, Switzerland, 2014; ISBN 978-3-319-04485-9.

48. Dohnal, M. Ignorance and uncertainty in reliability reasoning. Microelectron. Reliab. 1992, 32, $1157-1170$. [CrossRef]

49. Watson, S.R. The meaning of probability in probabilistic safety analysis. Reliab. Eng. Syst. Saf. 1994, 45, 261-269. [CrossRef]

50. Behera, D.; Chakraverty, S. Solving fuzzy complex system of linear equations. Inf. Sci. 2014, 277, $154-162$. [CrossRef]

51. Huang, C.-F.; Tsai, M.-Y.; Hsieh, T.-N.; Kuo, L.-M.; Chang, B.R. A study of hybrid genetic-fuzzy models for IPO stock selection. In Proceedings of the International Conference on Fuzzy Theory and it's Applications (iFUZZY), Taichung, Taiwan, 16-18 November 2012; pp. 357-362. 